\title{
THE RELATIONSHIP BETWEEN CALCIUM AND MAGNESIUM IN PEDIATRIC MYOCARDIAL PROTECTION
}

Michael Kronon, MD*

Kirk S. Bolling, MD

Bradley S. Allen, MD

Shaikh Rahman, MS

Tingrong Wang, MD

Ari Halldorsson, MD

Harold Feinberg, $\mathrm{PhD}$

Sponsor: Reneé S. Hartz, MD
Objective: We previously demonstrated that calcium can be harmful to the hypoxic neonatal heart. Despite the fact that magnesium inhibits membrane transport of calcium, few studies have examined whether magnesium can prevent the deleterious effects of calcium in cardioplegic solutions. Methods: Twenty neonatal piglets ( 5 to 18 days old) underwent 60 minutes of ventilator hypoxia (inspired oxygen fraction $8 \%$ to $10 \%$ ) followed by reoxygenation with the use of cardiopulmonary bypass before cardioplegic arrest to produce a clinically relevant hypoxic "stress" injury. The aorta was then crossclamped for 70 minutes with multidose blood cardioplegia. Ten piglets received a hypocalcemic $(0.2$ to $0.4 \mathrm{mmol} / \mathrm{L})$ cardioplegic solution without (group $1, n=5$ ) or with magnesium $(10 \mathrm{mEq} / \mathrm{L})$ (group II, $n=5$ ) supplementation. Ten other piglets were protected with a normocalcemic (1.0 to $1.2 \mathrm{mmol} / \mathrm{L}$ ) cardioplegic solution without (group III, $n=$ 5) or with magnesium (group $\mathrm{IV}, \boldsymbol{n}=\mathbf{5}$ ). Myocardial function was assessed by means of pressure volume loops and expressed as a percentage of control. Coronary vascular resistance was assessed during each cardioplegic infusion. Results: Adding magnesium to a hypocalcemic cardioplegic solution (groups I and II) had no effect: Both groups had complete preservation of postbypass systolic function (end-systolic elastance $101 \% \mathrm{vs}$ $104 \%)$ and preload recruitable stroke work (101\% vs $102 \%)$, minimal increase in diastolic stiffness (159\% vs $153 \%)$, and no difference in myocardial tissue edema $\mathbf{( 7 8 . 8 \%}$ vs $\mathbf{7 8 . 9 \%}$ ) or coronary vascular resistance. Conversely, when a normocalcemic cardioplegic solution was administered without magnesium supplementation (group III), the results were markedly poorer than results obtained with magnesium supplementation (group IV). Without magnesium, there was a marked reduction in postbypass systolic function (end-systolic elastance $49 \%$ vs $101 \% ; p<0.05$ ), increased diastolic stiffness $(276 \%$ vs $162 \%$; p $<0.05)$, decreased preload recruitable stroke work $(53 \%$ vs $102 \% ; p<0.05)$, increased myocardial tissue edema $(80.0 \%$ vs $78.9 \% ; p<0.05$ ), and a rise in coronary vascular resistance $(p<0.05)$. Magnesium supplementation of the normocalcemic cardioplegic solution, by contrast, resulted in complete functional recovery. Conclusions: This study demonstrates that (1) magnesium does not alter the cardioprotective effects of a hypocalcemic cardioplegic solution, (2) a normocalcemic cardioplegic solution is detrimental to neonatal myocardium subjected to a previous hypoxic stress, and (3) magnesium supplementation of normocalcemic cardioplegic solutions prevents the deleterious effects of calcium. (J Thorac Cardiovasc Surg 1997;114:1010-9)
From the Division of Cardiothoracic Surgery at the University of Illinois at Chicago, Chicago, III.

Read at the Seventy-seventh Annual Meeting of The American Association for Thoracic Surgery, Washington, D.C., May 4-7, 1997.

Received for publication May 7, 1997; revisions requested June 25, 1997; revisions received August 11, 1997; accepted for publication August 12, 1997.
Address for reprints: Bradley S. Allen, MD, Cardiothoracic Surgery Division, Suite 417 CSB (M/C 958), University of Illinois at Chicago, 840 South Wood St., Chicago, IL 606127323.

*Supported in part by the Pillsbury Fellowship.

Copyright ( 1997 by Mosby-Year Book, Inc.

$0022-5223 / 97 \$ 5.00+0 \quad \mathbf{1 2 / 6 / 8 5 3 6 6}$ 
W $\mathrm{e}^{1}$ have shown the superiority of hypocalcemic blood cardioplegic solutions in protecting hypoxic neonatal hearts. However, in clinical practice, there are often transient fluxes in the ionized calcium concentration of the cardioplegic solution because of variability in $\mathrm{pH}$, hemodilution, temperature, potassium, and systemic calcium levels. The ischemic neonatal myocardium is therefore at risk of exposure to potentially higher or lower calcium levels than originally intended, which may increase the risk of a calcium-mediated injury. This unintended transient calcium rise assumes even greater importance in pediatric myocardial protection, because immature myocytes are less able to handle a given calcium load than is the adult myocardium..$^{2,3}$ In addition, despite concerns over calcium injury, many pediatric surgeons continue to use normocalcemic cardioplegic solutions. Although magnesium has been shown to inhibit calcium membrane transport and thus prevent its intracellular accumulation in adults, few studies have examined the relationship of calcium and magnesium in neonatal myocardial protection. ${ }^{4-7}$ However, if magnesium inhibits calcium influx, it may prevent the injury that occurs from exposure of the ischemic myocardial cell to these higher calcium concentrations.

In view of the unique structural, functional, and metabolic characteristics of the neonatal heart, myocardial protective strategies and cardioplegic solutions must be studied in the infant heart if results are to be clinically applicable. Inclusion of stressed (hypoxic) hearts in any investigation of pediatric myocardial protection is also critically important, because calcium homeostasis becomes even more significant when the infant myocardium is altered by a preoperative stress such as hypoxia. ${ }^{1,3}$ This study therefore examines the relationship between calcium and magnesium in cardioplegic solutions with the use of an intact in vivo model that mimics the clinical conditions of the operating room in hypoxic (stressed) neonatal hearts.

\section{Materials and methods}

Twenty neonatal (5- to 18-day-old) piglets ( 3.5 to $5 \mathrm{~kg}$ ) were premedicated intramuscularly with ketamine, 40 $\mathrm{mg} / \mathrm{kg}$, and anesthetized with pentobarbital, $30 \mathrm{mg} / \mathrm{kg}$ intraperitoneally followed by $5 \mathrm{mg} / \mathrm{kg}$ intravenously each hour. The lungs were ventilated via a tracheotomy by means of a volume ventilator (Servo 900B, Siemens/ Elema, Solna, Sweden). All animals received humane care in compliance with the "Principles of Laboratory Animal Care" formulated by the National Society for Medical Research and the "Guide for the Care and Use of
Laboratory Animals" prepared by the National Academy of Sciences and published by the National Institutes of Health (NIH publication No. 96-03, revised 1996).

The femoral artery and vein were cannulated to monitor arterial pressure, for blood gas determinations, and for intravenous infusions. After left thoracotomy, the coronary sinus was cannulated for blood sampling and pressure monitoring via the ligated hemiazygos vein. The heart was exposed via a median sternotomy; and transducer-tipped catheters (Millar Instruments, Inc., Houston, Tex.) were placed into the left ventricle, thoracic aorta (via the internal thoracic artery), left atrium, and pulmonary artery. The signals were routed to a recorder (model 4586C, Hewlett-Packard Company, Palo Alto, Calif.) by means of signal conditioners (model $8805 \mathrm{C}$, Hewlett-Packard). A conductance catheter equipped with eight electrodes (Webster Laboratories, Baldwin Park, Calif.) was inserted through the left ventricular (LV) apex and the signals routed to a Sigma-5 dual-field signal conditioner processor (Leycon Cardiodynamics, Leiden, The Netherlands). After systemic heparinization (3 mg/ $\mathrm{kg}$ ), a thin-walled venous cannula (18F) and an aortic cainnula $(8 \mathrm{~F})$ were inserted into the right atrial appendage and left subclavian artery, respectively. An 18-gauge cardioplegia needle (DLP, Inc., Grand Rapids, Mich.) was inserted into the aortic root for delivery of cardioplegic solutions. Arterial blood gases, electrolytes, and hemoglobin levels (Blood Gas System 288, Ciba Corning, Medfield; Mass.) were measured every 15 minutes to ensure optimal levels. A heating blanket was placed below the piglet, and a heating pad was placed on the abdomen to maintain a constant core temperature of $37^{\circ}$ to $38^{\circ} \mathrm{C}$. External heat sources were discontinued during systemic cooling. The cardiopulmonary bypass (CPB) circuit was heparinized, primed with packed red cells from donor pigs, and made normocalcemic with calcium chloride. The hematocrit value was adjusted to $25 \%$ to $35 \%$ with $0.9 \%$ normal saline solution. A Baxter Univox membrane oxygenator (Baxter Healthcare Corporation, Irvine, Calif.) was used, and the systemic flow was adjusted to approximately $100 \mathrm{ml} / \mathrm{kg}$ per minute to maintain a continuously monitored aortic root pressure of 30 to $50 \mathrm{~mm} \mathrm{Hg}$.

Cardioplegia protocol. Cardioplegic solutions (CAPS Service, Research Medical Inc., Salt Lake City, Utah) are shown in Tables I and II. The aorta was crossclamped for 70 minutes and cardioplegic solution delivered by means of a protocol of 5 minutes of warm $\left(37^{\circ} \mathrm{C}\right)$ followed by 5 minutes of cold $\left(4^{\circ} \mathrm{C}\right)$ blood cardioplegic induction, a 2-minute cold $\left(4^{\circ} \mathrm{C}\right)$ multidose cardioplegic infusion every 20 minutes, and a 4-minute warm $\left(37^{\circ} \mathrm{C}\right)$ cardioplegic reperfusate ("hot shot") before aortic unclamping. Cardioplegic solution was infused at a continuously measured aortic pressure of 40 to $50 \mathrm{~mm} \mathrm{Hg}$. Immediately after the aorta was crossclamped all piglets were cooled to a systemic temperature of $25^{\circ} \mathrm{C}$, and rewarming to $37^{\circ} \mathrm{C}$ was initiated 16 minutes before aortic unclamping. All piglets were weaned from CPB with no inotropic support 30 minutes after aortic unclamping. Final functional and biochemical measurements were made 30 minutes later, after arterial blood gases and calcium and potassium levels were normalized. 
Table I. Warm blood cardioplegic solution

\begin{tabular}{lcll}
\multicolumn{1}{c}{$\begin{array}{c}\text { Cardioplegia } \\
\text { additive }\end{array}$} & $\begin{array}{c}\text { Volume } \\
\text { added }(\mathrm{ml})\end{array}$ & $\begin{array}{c}\text { Component } \\
\text { modified }\end{array}$ & $\begin{array}{c}\text { Concentration } \\
\text { delivered }^{*}\end{array}$ \\
\hline $\mathrm{KCl}(2 \mathrm{mEq} / \mathrm{ml})$ & 10 & $\mathrm{~K}^{+}$ & $8-10 \mathrm{mEq} / \mathrm{L}$ \\
Tham $(0.3 \mathrm{~mol} / \mathrm{L})$ & 225 & $\mathrm{pH}$ & $\mathrm{pH} 7.5-7.7$ \\
$\mathrm{CPD}$ & 225 & $\mathrm{Ca}^{+2}$ & $0.2-0.3 \mathrm{mmol} / \mathrm{L} \dagger$ \\
$\mathrm{MgCl}_{2}(2 \mathrm{mEq} / \mathrm{ml})$ & 24 & $\mathrm{Mg}^{+2}$ & $10-12 \mathrm{mEq} / \mathrm{L} \neq$ \\
Asparatate $/ \mathrm{glutamate}$ & 250 & Substrate & $13 \mathrm{mmol} / \mathrm{L}$ each \\
$\mathrm{D}_{50} \mathrm{~W}$ & 40 & Glucose & $<400 \mathrm{mg} / \mathrm{dl}$ \\
$\mathrm{D}_{50} \mathrm{~W}$ & 200 & Osmolarity & $380-400 \mathrm{mOsm}$ \\
\hline
\end{tabular}

Tham, Tromethamine; $C P D$, citrate-phosphate-dextrose; $D_{50} W, 50 \%$ dextrose in water

*When mixed in a 4:1 ratio with blood.

$†$ For normocalcemic cardioplegia, $\mathrm{CaCl}_{2}$ was added to make the ionized $\mathrm{Ca}^{+2} 1.1$ to $1.3 \mu \mathrm{mol} / \mathrm{L}$ when mixed in a $4: 1$ ratio with blood.

$\$ \mathrm{MgCl}_{2}$ was added only to groups II and IV (magnesium enrichment); groups I and III received the same solution except no $\mathrm{MgCl}_{2}$ was added.

Experimental groups. All piglets underwent 60 minutes of ventilator hypoxia by lowering the fraction of inspired oxygen to $8 \%$ to $10 \%$, producing an arterial oxygen tension of 25 to $35 \mathrm{~mm} \mathrm{Hg}$ and an arterial oxygen saturation of $65 \%$ to $70 \%$. Before hypoxemia, piglets were given transfusions as necessary to increase their hematocrit value to greater than $35 \%$. This simulates the chronic adaptive change of erythrocytosis, which increases oxygencarrying capacity, thus allowing ischemia to be avoided during hypoxia. At the end of 60 minutes all piglets were subjected to CPB at an inspired oxygen fraction of $100 \%$ for 5 minutes to produce a reoxygenation injury. ${ }^{1,8,9}$ Ten piglets were subjected to this cardioplegia protocol with a hypocalcemic $(0.2$ to $0.4 \mathrm{mmol} / \mathrm{L})$ cardioplegic solution. In five (group I) no exogenous magnesium was added to the cardioplegic solution, and in the other five (group II) magnesium was added to produce a concentration of approximately $10 \mathrm{mEq} / \mathrm{L}$ when mixed in a $4: 1$ ratio with blood. In 10 other piglets, calcium chloride was added to the cardioplegic solutions to make the ionized calcium concentration normal $(1.0$ to $1.2 \mathrm{mmol} / \mathrm{L})$ when mixed with blood in a $4: 1$ ratio. Five of these hearts were protected with solutions containing no magnesium (group III), and five received magnesium enrichment (group IV).

Myocardial performance. LV pressure and conductance catheter signals were amplified and digitized to inscribe LV pressure volume loops after first correcting for parallel conductance (myocardial tissue and blood viscosity) with the use of hypertonic saline solution according to the method of Baan, Van Der Velde, and Steendijk. ${ }^{10}$ A series of pressure volume loops was generated under varying conditions by transient occlusion of the inferior vena cava during an 8-second period of apnea. Measurements were made before hypoxia (baseline) and 30 minutes after $\mathrm{CPB}$ was discontinued.

The end-systolic and end-diastolic pressure volume relationships and the preload recruitable stroke work (PRSW) relationship were analyzed with the use of a computer graphics program (Spectrum, Bowman-Gray School of Medicine, Winston-Salem, N.C.) on a 486-33 $\mathrm{mHz}$ Dell personal computer. LV systolic performance
Table II. Cold blood cardioplegic solution

\begin{tabular}{lcll}
\hline $\begin{array}{c}\text { Cardioplegia } \\
\text { additive }\end{array}$ & $\begin{array}{c}\text { Volume } \\
\text { added }(\mathrm{ml})\end{array}$ & $\begin{array}{c}\text { Component } \\
\text { modified }\end{array}$ & $\begin{array}{c}\text { Concentration } \\
\text { delivered }\end{array}$ \\
\hline $\mathrm{KCl}(2 \mathrm{mEq} / \mathrm{ml})$ & 10 & $\mathrm{~K}^{+}$ & $8-10 \mathrm{mEq} / \mathrm{L}$ \\
Tham $(0.3 \mathrm{~mol} / \mathrm{L})$ & 200 & $\mathrm{pH}$ & $\mathrm{pH} 7.6-7.8$ \\
$\mathrm{CPD}$ & 50 & $\mathrm{Ca}^{+2}$ & $0.5-0.6 \mathrm{mmol} / \mathrm{L} \dagger$ \\
$\mathrm{MgCl}_{2}(2 \mathrm{mEq} / \mathrm{ml})$ & 18 & $\mathrm{Mg}^{+2}$ & $10-12 \mathrm{mg} / \mathrm{L}+$ \\
$\mathrm{D}_{50} \mathrm{~W}$ & 550 & Osmolarity & $340-360 \mathrm{mOsm}$ \\
\hline
\end{tabular}

Tham, Tromethamine; $C P D$, citrate-phosphate-dextrose; $D_{50} W, 50 \% \mathrm{dex}-$ trose in water.

"When mixed in a 4:1 ratio with blood.

$\ddagger$ For normocalcemic cardioplegia, $\mathrm{CaCl}_{2}$ was added to make the ionized $\mathrm{Ca}^{+2} 1.1$ to $1.3 \mu \mathrm{mol} / \mathrm{L}$ when mixed in a $4: 1$ ratio with blood.

$\$ \mathrm{MgCl}_{2}$ was added only to groups II and IV (magnesium enrichment); groups I and III received the same solution except no $\mathrm{MgCl}_{2}$ was added.

was determined from the descending slope of the endsystolic pressure volume relationship by means of linear regression analysis and designated as end-systolic elastance. End-diastolic compliance was determined from the exponential regression of the end-diastolic pressure volume relationship. Overall myocardial performance was assessed by PRSW, which was calculated as the integral of LV transmural pressure and cavity volume over each cardiac cycle. Functional measurements were expressed as percent recovery of baseline values with each piglet acting as its own control. After final hemodynamic measurements, all piglets were again subjected to $\mathrm{CPB}$ and cooled to $25^{\circ} \mathrm{C}$. Hearts were then arrested with cold $\left(4^{\circ} \mathrm{C}\right)$ blood cardioplegic solution and transmural LV biopsy specimens were obtained. Endocardial and epicardial portions were separated, frozen quickly in liquid nitrogen, and stored for biochemical analysis. Separate samples were obtained to measure myocardial water.

Physiologic measurements. Coronary vascular resistance (CVR) was determined during each cardioplegic infusion by measuring coronary sinus pressure and cardioplegic flow once a constant infusion rate with an aortic root pressure between 40 and $50 \mathrm{~mm} \mathrm{Hg}$ was achieved. CVR was calculated by means of the following formula:

$$
\text { CVR }\left(\text { dynes } / \mathrm{sec} / \mathrm{cm}^{-5}\right)=\frac{\mathrm{CIP}-\mathrm{CSP}}{\mathrm{CFR}} \times 80
$$

where CIP = cardioplegia infusion pressure, CSP = coronary sinus pressure, and CFR = cardioplegia flow rate.

Biochemical analysis. Myocardial samples were crushed in a liquid nitrogen-cooled mortar and pestle and lyophilized (Savant Speed Vac Systems, Farmingdale, N.Y.). The adenosine pool was determined according to the method of Sarin and associates. ${ }^{11}$ A 10 to $15 \mathrm{mg}$ sample of dry tissue was extracted with $0.6 \mathrm{~mol} / \mathrm{L}$ perchloric acid, the protein-free supernatant neutralized by a mixture of $\mathrm{KHCO}_{3}$ in $0.5 \mathrm{~mol} / \mathrm{L}$ Tris buffer $(\mathrm{pH} 7.5)$, and a neutralized solution allowed to stand at $4^{\circ} \mathrm{C}$ to precipitate $\mathrm{KCLO}_{4}$. Aliquots of the neutralized extract were chromatographed with the use of a high-performance liquid chromatography device (Waters, Inc., Milford, Mass.) equipped with a Waters Nova-Pak column. The 


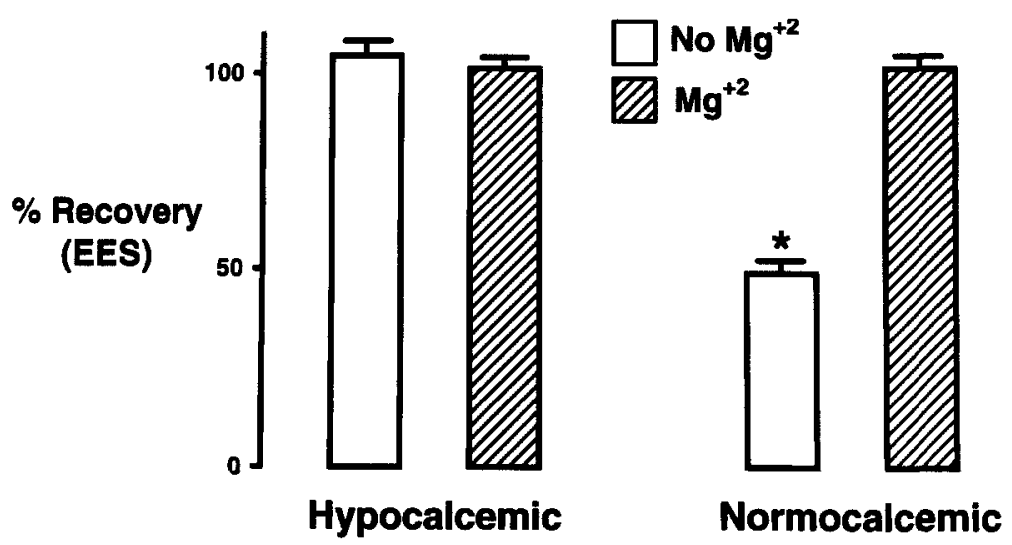

Fig. 1. LV systolic function as measured by the end-systolic elastance ( $E E S$ ) and expressed as a percentage of baseline values. Systolic function is completely preserved, independent of the presence of magnesium, in hearts protected with a hypocalcemic cardioplegic solution. Hearts protected with a normocalcemic cardioplegic solution alone exhibited marked loss of systolic function. In contrast, magnesium enrichment of the normocalcemic cardioplegic solution offset the detrimental effects of high levels of calcium, resulting in complete return of systolic function. ${ }^{*} p<0.001$.

adenosine pool was isocratically eluted with a mobile phase consisting of ammonium phosphate, $0.1 \mathrm{mmol} / \mathrm{L}$, and tetrabutylammonium hydroxide, $0.5 \mathrm{nmol} / \mathrm{L}(\mathrm{pH} 5.0)$, and detected at $233 \mathrm{~nm}$. Adenosine triphosphate (ATP) and diphosphate (ADP) levels were expressed as micrograms per gram of dry tissue.

Myocardial water. Ventricular samples were placed in preweighed vials and dried to a constant weight at a temperature of $85^{\circ} \mathrm{C}$. The percent myocardial water was calculated by means of the formula:

$$
\% \text { Myocardial water }=\frac{\text { Wet weight }- \text { Dry weight }}{\text { Wet weight }} \times 100
$$

Statistics. Data were analyzed with the use of JMP V2.0 software (SAS Institute, Inc., Cary, N.C.) on a Macintosh IIVX computer (Apple Inc., Cupertino, Calif.). Group data are expressed as mean \pm standard error of the mean. Paired Student's $t$ test and two-way analysis of variance with interaction (factorial analysis) were used for comparison of variables among experimental groups. If the analysis of variance revealed a significant interaction, a pairwise test of individual group means was contrasted by way of multiple comparisons (Tukey's test), using a level of significance of $p<0.05$.

\section{Results}

The groups did not differ with regard to prebypass baseline values of LV contractility (end-systolic elastance $33 \pm 1)$, diastolic compliance $(0.03 \pm 0.01)$, or PRSW (75 \pm 3 ). Hypoxia resulted in an increase in heart rate from 130 to 150 beats/min to 190 to 220 beats/min, a decrease in systemic vascular resistance, and an increase in pulmonary vascular resistance, but it did not significantly affect cardiac output. All piglets tolerated 60 minutes of hypoxia with stable hemodynamics.

Hemodynamic and physiologic measurements. Results are depicted in Figs. 1 to 4. There was no change or difference in the $\mathrm{X}$-axis intercept point for end-systolic elastance (prebypass $6.9 \pm 0.1$, postbypass $6.8 \pm 0.2$ ) or PRSW (prebypass $10.4 \pm 0.2$, postbypass $10.1 \pm 0.2$ ) between prebypass (baseline) and postbypass values in any experimental group. Therefore the change in slope of end-systolic elastance and PRSW can be interpreted to express variability in the contractile state of the myocardium compared with control values. Adding magnesium to a hypocalcemic cardioplegic solution (groups I and II) had no statistically significant effect on myocardial function, inasmuch as both groups had complete preservation of postbypass systolic function $(101 \% \pm 2 \%$ vs $104 \% \pm 3 \%)$ and PRSW $(102 \% \pm 2 \%$ vs $100 \% \pm 1 \%)$ and a minimal increase in diastolic stiffness $(159 \% \pm 2 \%$ vs $153 \%$ $\pm 12 \%$ ). Conversely, using a normocalcemic cardioplegic solution without magnesium supplementation (group III) resulted in poorer results than those obtained with magnesium supplementation (group IV): a marked reduction in postbypass systolic function $(49 \% \pm 4 \%$ vs $101 \% \pm 1 \% ; p<0.0001)$, increased diastolic stiffness $(276 \% \pm 9 \%$ vs $162 \% \pm$ $3 \% ; p<0.0001)$, and decreased PRSW $(53 \% \pm 3 \%$ vs $102 \% \pm 2 \% ; p<0.0001)$. Use of magnesiumenriched cardioplegic solution, by contrast, resulted in complete functional recovery. There were no 

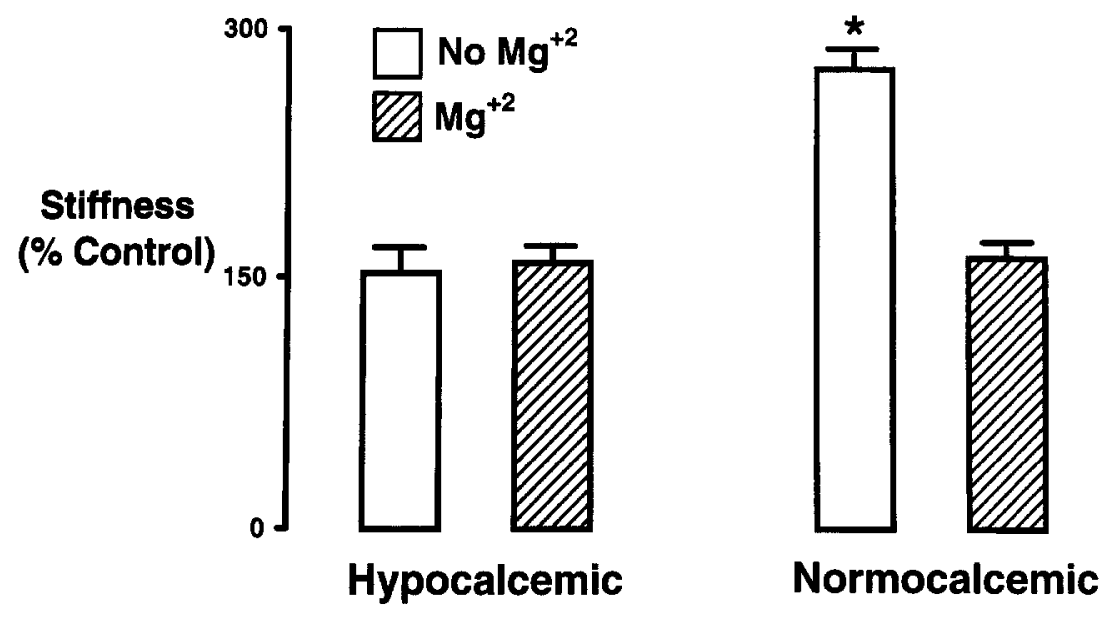

Fig. 2. LV diastolic compliance as measured by the end-diastolic pressure volume relationship and expressed as percent increased stiffness compared with baseline values. Only a minimal increase in diastolic stiffness is observed in hearts protected with hypocalcemic cardioplegic solutions independent of the presence of magnesium. A marked increase in diastolic stiffness is observed in hearts protected with a normocalcemic solution without magnesium enrichment. Conversely, when magnesium is added to the normocalcemic cardioplegic solution, diastolic compliance is maintained. ${ }^{*} p<0.001$.

statistically significant differences $(p>0.2)$ in CVR among groups I, II, and IV (Fig. 4). In contrast, there was a marked increase in CVR in hearts receiving a normocalcemic cardioplegic solution without magnesium enrichment (group III), implying that these hearts had sustained a vascular injury. Because cardioplegic solution was delivered over time at a given pressure, this also resulted in a lower total dose of cardioplegic solution in these hearts.

Tissue studies. Endocardial tissue results are summarized in Table III. In contrast to the functional results, magnesium supplementation of a hypocalcemic cardioplegic solution (group II) resulted in better preservation of ATP levels ( $F=$ $9.06, p=0.008$ ). Conversely, use of a normocalcemic cardioplegic solution without magnesium (group III) significantly depressed ATP levels as a result of a calcium-mediated injury. This fall in myocardial ATP was prevented by adding magnesium to the normocalcemic solution (group IV), implying that magnesium blocks the deleterious effects of calcium. The ATP/ADP ratio, which reflects the ability of the mitochondria to phosphorylate ADP to ATP, was markedly reduced when a normocalcemic cardioplegic solution without magnesium (group IV) was used, further suggesting mitochondrial damage as a result of high calcium levels $(F=125, p<0.0001)$. This group also had the highest percentage of myocar- dial water of any experimental group, indicating the greatest degree of myocardial cell damage $(F=68.4, p<0.0001)$.

\section{Discussion}

This study demonstrates that in a clinically relevant intact animal model simulating conditions in the operating room, (1) magnesium does not significantly alter the cardioprotective effects of a hypocalcemic cardioplegic solution, (2) a normocalcemic cardioplegic solution is detrimental to neonatal myocardium subjected to a previous hypoxic stress, and (3) adding magnesium to a normocalcemic cardioplegic solution prevents the deleterious effects of calcium.

Intracellular accumulation of calcium during ischemia and reperfusion has been associated with cellular injury. ${ }^{1-3,12,13}$ Several mechanisms of injury have been proposed, including increased ATP use through activation of calcium-dependent ATPases; impaired ATP synthesis resulting from mitochondrial damage from calcium uptake; activation of numerous calcium-dependent degradative enzymes such as proteases, lipases, and phospholipases; and calcium enhancement of various free radical-mediated reactions. ${ }^{2,14,15}$ The neonatal heart may be more susceptible to a calcium-mediated cellular injury because the sarcoplasmic reticulum of the immature myocardium has a diminished capacity to 


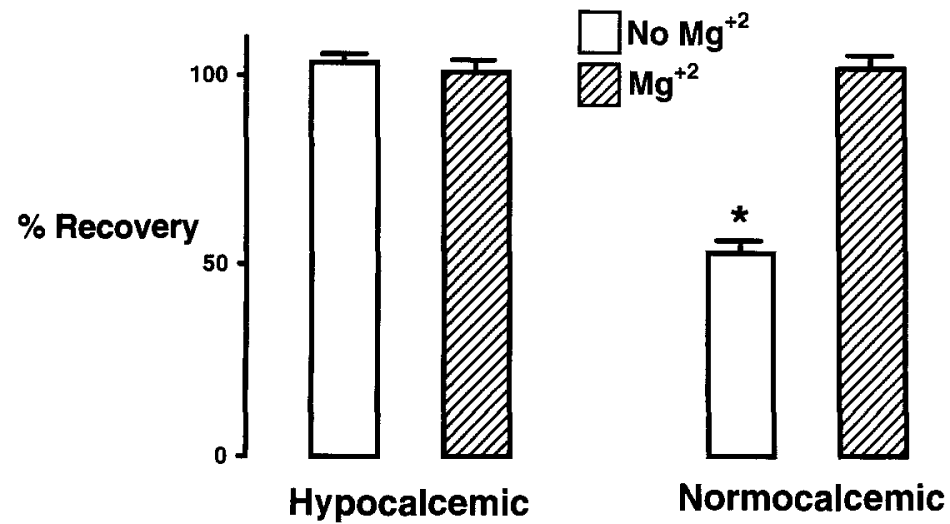

Fig. 3. Overall LV myocardial function measured by PRSW and expressed as percent recovery compared with baseline values. Global myocardial function is completely preserved, independent of the presence of magnesium, in hearts protected with a hypocalcemic cardioplegic solution. In hearts protected with a normocalcemic cardioplegic solution, there is marked loss of global myocardial function in the absence of magnesium enrichment. Conversely, magnesium enrichment offsets the detrimental effects of high-calcium cardioplegic solution, preserving PRSW. * $p<0.001$.

sequester calcium and because of different characteristics of the calcium transport system. ${ }^{2,3}$

Despite the fact that magnesium has been shown to prevent the intracellular accumulation of calcium during global myocardial ischemia, few studies have examined whether magnesium can prevent the deleterious effects of calcium in cardioplegic solutions. ${ }^{3,5,7,15,16}$ High magnesium concentration has been suggested to inhibit calcium entry into the cell by displacing calcium from binding sites in the sarcolemmal membrane (1-type calcium channels) and by hyperpolarization of the sarcolemmal membrane. ${ }^{7,15,17}$ It has also been postulated that extracellular magnesium, when supplied before global myocardial ischemia, acts by raising cytosolic magnesium concentrations, thereby reducing the release of calcium from the sarcoplasmic reticulum. ${ }^{15,17}$ Finally, replenishing magnesium in ischemic hearts may diminish the depletion of ATP stores, thereby protecting the phosphorylation function of mitochondria during and after reperfusion..$^{5,15}$

An increasing number of infants with cyanotic congenital heart disease are undergoing primary surgical repair. Although this may be preferable to palliation, it subjects the immature hypoxic heart to $\mathrm{CPB}$ and high levels of oxygen, which produce an unintended reoxygenation injury. ${ }^{1,8,9,18}$ This oxygen-derived free radical-mediated injury results in myocardial depression and may explain why impairment of ventricular function is common after apparently satisfactory surgical correction of cyanotic congenital defects. ${ }^{13,19-21}$ Despite the prevalence of this condition in the pediatric population, few studies of pediatric myocardial protection have included hypoxic hearts, and none have investigated the relationship between calcium and magnesium in cardioplegic solutions. Including these hearts is extremely important, because hypoxia may profoundly alter the neonatal myocardium, thus influencing the effects of a given cardioplegic solution. ${ }^{1,3,22,23} \mathrm{We}$ therefore examined the interaction of calcium and magnesium levels in cardioplegic solutions in neonatal hearts using a clinically relevant stress (hypoxic) model that mimics conditions of the operating room.

Hearts protected with a hypocalcemic cardioplegic solution had complete preservation of myocardial function regardless of the presence or absence of magnesium (see Figs. 1 to 3). This is in accordance with our previous findings showing that adequate myocardial protection in the hypoxically stressed heart is provided by a hypocalcemic cardioplegic solution. ${ }^{1}$ However, ATP levels were slightly higher in hearts protected with magnesiumenriched hypocalcemic cardioplegia, suggesting a possible benefit to magnesium, even in the presence of low levels of calcium in the cardioplegic solution. Calcium can increase myocardial wall tension even during potassium arrest; hence calcium is a determinant of energy requirements during cardioplegic arrest. ${ }^{7,15,24}$ Therefore, by blocking calcium entry during ventricular asystole, magnesium may lower metabolic demands by decreasing wall tension, thus improving ATP levels. The ischemic (crossclamp) 


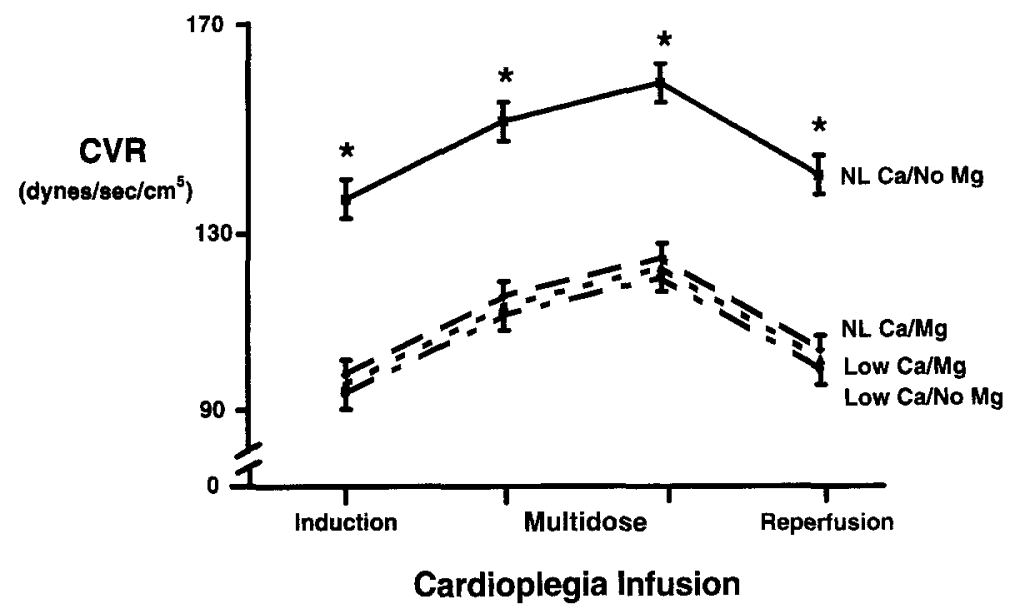

Fig. 4. CVR measured during each cardioplegic infusion. There is no difference in CVR in hearts protected with a hypocalcemic solution or a normocalcemic solution enriched with magnesium. Conversely, there is a marked rise in CVR when a normocalcemic cardioplegic solution was infused in the absence of magnesium enrichment, indicating a coronary vascular injury. ${ }^{*} p<0.001$.

time was relatively short in this study, and the neonatal myocardium may be more tolerant of ischemia than the adult myocardium. ${ }^{3,13}$ Because the reperfusion injury depends on the duration of ischemia, this may have accounted for the lack of greater improvement seen with magnesium enrichment of hypocalcemic solutions.

Subjecting the hypoxically stressed neonatal heart to a normocalcemic cardioplegic solution profoundly altered the effect of magnesium supplementation. Hypoxic neonatal hearts sustain a significant cellular injury when protected with a normocalcemic cardioplegic solution. ${ }^{1}$ This injury is manifested by depression in postbypass myocardial and vascular dysfunction. In contrast, adding magnesium to a normocalcemic solution not only protects the heart from further damage, but facilitates repair of the injury caused by hypoxia and reoxygenation, resulting in complete preservation of myocardial and vascular endothelial cell function (see Figs. 1 to 4). This implies that magnesium offsets the detrimental effects of high calcium concentrations in cardioplegic solutions.

Vascular function was determined by measuring CVR during each infusion of cardioplegic solution when the heart was arrested and the flow rate and infusion pressure had reached a steady state. Although the myocardial metabolic demands and thus CVR may change between warm and cold cardioplegia, they should be identical for each heart at any given temperature. This is precisely what was seen in hearts protected hypocalcemic cardioplegia or nor- mocalcemic cardioplegia with magnesium enrichment. In contrast, there was a marked increase in CVR during each cardioplegic infusion in hearts protected with a normocalcemic solution without added magnesium (Fig. 4) This appears to reflect a derangement in vascular function resulting from higher calcium levels without the protective benefit of magnesium enrichment. This increased CVR may have also resulted in a less homogeneous distribution of cardioplegic solution, as well as a lower volume of solution infused, thereby further compromising myocardial protection during cardiac arrest.

The hypoxic heart has been shown both clinically and experimentally to have an increased susceptibility to ATP depletion during surgically induced ischemia. $^{23,25}$ Elevated calcium concentration during ischemia accelerates the breakdown of ATP by activation of calcium-dependent ATPases. ${ }^{2,15,26}$ This energy depletion may further impair ATPdependent mechanisms that maintain calcium homeostasis. Postbypass tissue ATP levels seem to support this hypothesis. In both hypocalcemic cardioplegia groups, ATP levels and the ATP/ADP ratio were preserved (see Table III). Conversely, endocardial ATP levels were markedly reduced in hearts protected with normocalcemic cardioplegia without added magnesium (group IV). In addition, the ATP/ADP ratio also fell in this group, which seems to indicate that there is indeed some mitochondrial damage resulting in a decreased ability to convert ADP to ATP. However, high-energy phosphates and mitochondrial function were preserved 
in hearts protected with a magnesium-enriched normocalcemic cardioplegic solution, implying that magnesium limits the detrimental effects of high calcium concentrations. Because low postischemic ATP levels in infants correlate with poor postoperative ventricular function, these findings, along with the functional data, suggest that magnesium-free normocalcemic cardioplegia provides inadequate myocardial protection in hypoxic hearts. Indeed, these findings parallel those seen clinically in patients with the tetralogy of Fallot, in whom ATP levels are significantly depressed and ventricular function is often decreased after apparently successful surgical correction. ${ }^{20,21}$

Although our model of acute hypoxia does not allow for the chronic adaptive changes that may occur in cyanotic newborn infants, it does subject the heart to a clinically relevant stress. Including stressed hearts in cardioplegia investigation is extremely important, because these hearts are more vulnerable to ischemia and more sensitive to methods of myocardial protection., ${ }^{12}$ Several studies have documented a similar oxygen-mediated injury with reoxygenation of the chronically hypoxic infant, and we recently reported an identical injury in 21 cyanotic infants using the same biochemical parameters as used in our acute experimental studies. ${ }^{8,9,18,27,28}$ Indeed, these studies suggest that the injury after chronic cyanosis may be even more severe than after acute hypoxia. Our experimental model of acute hypoxia does not cause significant depletion of ATP stores. ${ }^{9,29}$ Conversely, chronically cyanotic hearts may be predisposed to accelerated depletion of these high-energy compounds during periods of increased myocardial oxygen demands. ${ }^{13,}$, 30, 31 Because the presence of magnesium has been shown to improve metabolic and functional recovery after ischemia by helping to prevent ATP depletion, this further suggests that magnesium-enhanced cardioplegic solutions should be used in cyanotic infants. $3,5,1.5$

Magnesium has been shown to improve myocardial protection by preventing the intracellular accumulation of calcium during ischemia and reperfusion. $3,5,6,15$ This study supports this effect. However, the improvement seen in hypoxic hearts protected with hypocalcemic cardioplegia cannot be explained by this mechanism, because all piglets had complete preservation of preoperative myocardial function regardless of the presence of magnesium in the solution. Therefore the question of whether magnesium supplementation is necessary when us-
Table III. Endocardial tissue

\begin{tabular}{|c|c|c|c|}
\hline Group & $\begin{array}{c}A T P \\
(\mu g / g m d r y w t)\end{array}$ & $\begin{array}{l}\text { ATP/ADP } \\
\text { ratio }\end{array}$ & $\begin{array}{l}\text { Myocardial } \\
\text { water }(\%)\end{array}$ \\
\hline $\begin{array}{l}\text { Low } \mathrm{Ca}^{+2} / \mathrm{no}^{\mathrm{Mg}^{+2}} \\
\quad \text { (group I) }\end{array}$ & $15.1 \pm 0.7$ & $4.2 \pm 0.2$ & $78.8 \pm 0.6$ \\
\hline $\begin{array}{l}\text { Low } \mathrm{Ca}^{+2} / \mathrm{Mg}^{+2} \\
\text { (group II) }\end{array}$ & $17.5 \pm 0.4^{*}$ & $4.3 \pm 0.6$ & $78.9 \pm 0.2$ \\
\hline $\begin{array}{l}\text { High } \mathrm{Ca}^{+2} / \mathrm{no}^{\mathrm{Mg}^{+2}} \\
\quad \text { (group III) }\end{array}$ & $12.1 \pm 0.9^{*}$ & $2.3 \pm 0.2^{*}$ & $80.0 \pm 0.2 *$ \\
\hline $\begin{array}{l}\mathrm{High} \mathrm{Ca}^{+2} / \mathrm{Mg}^{+2} \\
\text { (group IV) }\end{array}$ & $15.6 \pm 0.3$ & $4.1 \pm 0.3$ & $78.9 \pm 0.3$ \\
\hline
\end{tabular}

ing a hypocalcemic cardioplegic solution remains unanswered. In clinical practice, however, it is more difficult to precisely regulate the cardioplegic calcium concentration because of transient variables such as $\mathrm{pH}$, temperature, plasma volume, and different bypass calcium concentrations. As a result, the patient is at risk of exposure to higher than intended calcium levels. This elevated calcium content cannot be safely prevented by further decreasing the already minimal $(0.2$ to $0.4 \mathrm{mmol} / \mathrm{L})$ ionized calcium level because of the risk of causing a calcium paradox. The addition of magnesium may solve this dilemma by allowing for the safe use of higher cardioplegic calcium concentrations. Furthermore, even in the presence of hypocalcemic cardioplegic solutions, other inhibitors of calcium entry (i.e., calcium channel blockers) have been shown to further enhance myocardial protection by limiting intracellular calcium accumulation; and in this study, ATP levels were highest when magnesium enrichment was combined with hypocalcemic solutions (group 1). Therefore we will continue to advocate the use of magnesium in hypocalcemic cardioplegic solutions until this issue is further investigated.

In summary, this study demonstrates that in a clinically relevant model, magnesium does not significantly alter the cardioprotective effects of a hypocalcemic cardioplegic solution in hypoxic hearts subjected to a short ischemic interval. Use of a normocalcemic cardioplegic solution is detrimental to the hypoxic neonatal myocardium, resulting in poor myocardial protection. In contrast, magnesium enrichment prevents the deleterious effects of normocalcemic cardioplegic solutions and thus provides markedly superior myocardial protection. Inasmuch as many pediatric heart surgeons use moderate calcium concentrations in their cardioplegic solu- 
tions, this study suggests that the routine addition of magnesium to cardioplegic solutions may improve myocardial protection in the cyanotic infant.

\section{REFERENCES}

1. Bolling KS, Kronon M, Allen BS, Ramon S, Wang T, Hartz $\mathrm{R}$, et al. Myocardial protection in normal and hypoxically stressed neonatal hearts: the superiority of hypocalcemic versus normocalcemic blood cardioplegia. J Thorac Cardiovasc Surg 1996;112:1193-201.

2. Aoki M, Nomura F, Kawata H, Mayer JE Jr, Effect of calcium and preischemic hypothermia on recovery of myocardial function after cardioplegic ischemia in neonatal lambs. J Thorac Cardiovasc Surg 1993;105:207-13.

3. Castaneda AR, Jonas RA, Mayer JE Jr, Hanley FL. Myocardial preservation in the immature heart. In: Castaneda AR, Jonas RA, Mayer JE Jr, Hanley FL, editors. Cardiac surgery of the neonate and infant. Philadelphia: WB Saunders; 1994. p. 41-54.

4. Hearse D, Humphrey S, Chain E. Abrupt reoxygenation of the anoxic potassium-arrested perfused rat heart: a study of myocardial enzyme release. J Mol Cell Cardiol 1973;5:395407.

5. Hearse DJ, Stewart DA, Braimbridge MV. Myocardial protection during ischemic cardiac arrest: the importance of magnesium in cardioplegic infusates. $\mathrm{J}$ Thorac Cardiovasc Surg 1978;75:877-85.

6. Ihnken K, Morita K, Buckberg GD, Matheis G, Sherman MP, Allen BS, et al. Studies of hypoxemic/reoxygenation injury: without aortic clamping. II. Evidence for reoxygenation damage. J Thorac Cardiovasc Surg 1995;110:1171-81.

7. Lansman JB, Hess P, Tsien RW. Blockade of current through single calcium channels by $\mathrm{Cd}^{2+}, \mathrm{Mg}^{2+}$, and $\mathrm{Ca}^{2+}$ : voltage and concentration dependence of calcium entry into the pore. J Gen Physiol 1986;88:321-47.

8. Buckberg GD. Studies of hypoxemic/reoxygenation injury. I. Linkage between cardiac function and oxidant damage. J Thorac Cardiovasc 1995;110:1164-70.

9. Bolling KS, Halldorsson A, Allen BS, Rahman SK, Wang T, Kronon M, et al. Prevention of the hypoxic reoxygenation injury with the use of a leukocyte-depleting filter. $\mathbf{J}$ Thorac Cardiovasc Surg 1997;113:1081-90.

10. Baan J, Van Der Velde E, Steendijk P. Ventricular pressure volume relations in vivo. Eur Heart J 1992;13(Suppl E):2-6.

11. Sarin M, Buinevicius Z, Levitsky S, Feinberg H. Isocratic high-performance liquid chromatographic analysis of myocardial creatine phosphate and adenine nucleotides. J Chromatogr 1991;563:129-33.

12. Buckberg GD, Allen BS. Myocardial protection management during adult cardiac operations. In: Baue AE, Geha AS, Hammond GL; Laks H, Naunheim KS, editors. Glenn's thoracic and cardiovascular surgery. 6th ed. Stamford (CT): Appleton \& Lange; 1995. p. 1653-87.

13. Hammon JW Jr. Myocardial protection in the immature heart. Ann Thorac Surg 1995;60:839-42.

14. Rebeyka I, Hanan SA, Borges MR, Lee KF, Yeh T Jr, Tuchy GE, et al. Rapid cooling contracture of the myocardium. J Thorac Cardiovasc Surg 1990;100:240-9.

15. Tsukube T, McCully JD, Federman M, Krukenkamp IB, Levitsky S. Developmental differences in cytosolic calcium accumulation associated with surgically induced global isch- emia: optimization of cardioplegic protection and mechanism of action. J Thorac Cardiovasc Surg 1996;112:175-84.

16. Tsukube T, McCully JD, Faulk EA, Federman M, LoCicero II, Krukenkarnp IB, et al. Magnesium cardioplegia reduces cytosolic and nuclear calcium and DNA fragmentation in the senescent myocardium. Ann Thorac Surg 1994;58:1005-11.

17. Boland R, Martonosi A, Tillack TW. Developmental changes in the composition and function of sarcoplasmic reticulum. J Biol Chem 1974:249:612-23.

18. Hirschl R, Heiss K, Bartlett R. Severe myocardial dysfunction during extracorporeal membrane oxygenation. J Pediatr Surg 1992;27:48-53.

19. Bull C, Cooper J, Stark J. Cardioplegia protection of the child's heart. J Thorac Cardiovase Surg 1984;88:287.

20. Jarmakani JM, Graham TP, Canent RV, Jewett PH. Left heart function in children with tetralogy of Fallot before and after palliative or corrective surgery. Circulation 1972;46:47890 :

21. Rocchini AP, Keane JF, Castaneda AR, Nadas AS. Left ventricular function following attempted surgical repair of tetralogy of Fallot. Circulation 1978;57:798-802.

22. Fujiwara $T$, Kurtts $T$, Anderson W, Heinke J, Mayer J. Myocardial protection in cyanotic neonatal lambs. $\mathbf{J}$ Thorac Cardiovasc Surg 1988;96:700-10.

23. Silverman N, Kohler J, Levitsky S, Pavel D, Fang R, Feinberg H. Chronic hypoxemia depresses global ventricular function and predisposes to depletion of high energy phosphates during cardioplegic arrest: implications for surgical repair of cyanotic congenital heart defects. Ann Thorac Surg 1984;37: 304-8.

24. Burkhoff D, Kalil-Filho R, Gerstenblith G. Oxygen consumption is less in rat hearts arrested by low calcium than by high potassium at fixed flow. Am J Physiol 1990;259:H1142-7.

25. Del Nido PJ, Mickle DAG, Wilson GJ, Benson LN, Weisel $\mathrm{RD}$, Coles JG, et al. Inadequate myocardial protection with cold cardioplegic arrest during repair of tetralogy of Fallot. J Thorac Cardiovasc Surg 1988;95:223-9.

26. Jarmakani JM, Nagatomo T, Langer GA. The effect of calcium and high phosphate compounds on myocardial contracture in the newborn and adult rabbit. J Mol Cell Cardiol 1978;10:1017-23.

27. Allen BS, Rahman SK, Ilbawi M, Feinberg H, Bolling KS, Kronon M. The detrimental effects of cardiopulmonary bypass in cyanotic infants: preventing the reoxygenation injury. Society of Thoracic Surgeons 1997; Thirty-third Annual Meeting: Abstract.

28. Martin G, Short B, Abbott C, O'Brien A. Cardiac stun in infants undergoing extracorporeal membrane oxygenation. J Thorac Cardiovasc Surg 1991;101:607-11.

29. Bolling KS, Kronon M, Allen BS, Wang $T$, Ramon $S$, Feinberg $\mathrm{H}$. Myocardial protection in normal and hypoxically stressed neonatal hearts: the superiority of blood versus crystalloid cardioplegia. J Thorac Cardiovasc Surg 1997;113: 994-1005.

30. Boucek RJ Jr, Kasselberg AG, Boerth RC, Parrish MD, Graham TP Jr. Myocardial injury in infants with congenital heart disease: evaluation by creatine kinase MB isoenzyme analysis. Am J Cardiol 1982;50:129-35.

31. Graham TP Jr, Erath HG Jr, Buckspan GS, Fisher RD. Myocardial anaerobic metabolism during isoprenaline infusion in a cyanotic animal model: possible cause of myocardial 
dysfunction in cyanotic congenital heart disease. Cardiovasc Res 1979;13:401-6.

\section{Discussion}

Dr. Tirone E. David (Toronto, Ontario, Canada). Dr. Allen, is magnesium equally important for the mature heart?

Dr. Allen. Yes. I believe magnesium is very important in both the immature and the mature heart. We now add magnesium to all our cardioplegic solutions and have excellent results in more than 300 pediatric and adult patients.

Dr. David. Is it important only with blood cardioplegia?

Dr. Allen. I firmly believe magnesium supplementation is important in both crystalloid and blood cardioplegic solutions. Dr. Hearse demonstrated years ago that adding magnesium to St. Thomas' Hospital solution improved myocardial protection, and other investigators have found similar benefits with blood cardioplegia. So far as I know, however, this is the first time magnesium has been shown to be beneficial in the neonatal heart and to counteract the detrimental effects of normocalcemic cardioplegia.

Dr. Sidney Levitsky (Boston, Mass.). We have been using magnesium added to normocalcemic blood cardioplegic solutions both experimentally and clinically. What is your hypothesis to explain your observation that ATP is decreased without the use of magnesium? Does magnesium added to cardioplegia have an effect on ATP synthesis or breakdown during surgically induced myocardial ischemia?
Dr. Allen. I am well aware of your extensive work in this field. You are partially responsible for stimulating my interest in this area of research. I believe magnesium limits extracellular calcium entry and reduces the release of calcium from the sarcoplasmic reticulum. This lowers intracellular calcium levels and helps preserve ATP by two mechanisms. First, it prevents activation of calcium-dependent ATPases. Second, calcium increases myocardial wall stress even during potassium arrest. If wall stress is decreased by limiting intracellular calcium, then ATP use is minimized, resulting in improved myocardial preservation and higher ATP levels.

Dr. D. Glenn Pennington (Winston Salem, N.C.). Do you think this effect occurs merely in a hypoxic heart? For example, in an infant without cyanotic heart disease, do these same rules apply?

Dr. Allen. On the basis of numerous studies from our laboratory, as well as those of other investigators, we now add magnesium to all our cardioplegic solutions. As to your question concerning specifically noncyanotic infants, I believe magnesium supplementation is beneficial in all patients because most patients undergoing surgery do not have "normal" hearts. Those infant hearts not stressed by hypoxia are usually subjected to pressure or volume overload as a result of their cardiac defect. Similarly, most adult hearts are stressed by either hypertrophy or ischemia. Inasmuch as we therefore operate on very few "normal" hearts, either in adults or in children, I believe magnesium enrichment should always be used, because beneficial effects of magnesium are most likely to be seen in stressed hearts. 